\title{
A study of iris melanoma in Northern Ireland
}

\author{
J N McGALLIARD AND P B JOHNSTON \\ From the Department of Ophthalmology, Royal Victoria Hospital, Grosvenor Road, Belfast BT12 6BA, \\ Northern Ireland
}

SUMMARY A retrospective study of all cases of iris melanoma in Northern Ireland over a 15-year period was undertaken. A total of 18 cases were identified. Of these, nine were histologically proved to be iris melanomas of various types. Within the period of follow-up two patients died from metastatic deposits. In both cases invasion of the anterior face of the ciliary body was present on histological examination. The implications for management are discussed.

Malignant melanomas of the uveal tract continue to pose considerable problems in treatment. Melanoma of the iris accounts for $3-10 \%^{12}$ of all uveal melanomas, and the indication for the surgical treatment of this tumour can be difficult in view of the reported low risk of metastatic spread. Nevertheless there have been well documented instances of death due to metastatic disease from iris melanoma. ${ }^{34}$

We report our experience with all cases of iris melanomas seen in our department over the past 15 years.

\section{Materials and methods}

The records of all patients with iris melanoma were retrieved through medical indexing, theatre records, and fluorescein angiography records of the Royal Victoria Hospital, Belfast, for 1973-87. Since our hospital is the regional centre for Northern Ireland it can be taken that the incidence recorded in our study represents the prevalence in the population served $\left(1.4 \times 10^{6}\right)$.

\section{Results}

In our series nine patients had histologicaly proved iris melanomas, and nine other iris lesions were clinically diagnosed as being melanomas but were not subjected to biopsy or excision. The average age of the patients treated surgically was 57 years (range 43$79)$. The average age of those who were conservatively managed was 66 years (range 51-74).

Table 1 shows the patients who were managed by observation alone. Of these nine patients four gave a history of a melanotic lesion on the iris since child-

Correspondence to J N McGalliard, FRCS.
Table 1 Patients managed by observation alone

\begin{tabular}{lllrll}
\hline $\begin{array}{l}\text { Patient, } \\
\text { age, sex }\end{array}$ & Eye & Location & $\begin{array}{l}\text { Follow-up } \\
(y r)\end{array}$ & Growth & IFA \\
\hline A, 73, M & R & Inferior & 11 & - & \\
B, 74, M & R & Inferotemporal & 4 & - & \\
C, 55, M & L & Inferotemporal & 12 & - & Vessels \\
D,74, M & R & Inferonasal & 2 & - & Vessels \\
E, 62, M & L & Inferior & 6 & - & \\
F, 51, M & R & Inferotemporal & 6 & + & Vessels \\
G,74, F & R & Superonasal & 5 & - & Vessels \\
H, 61, F & L & Inferotemporal & 5 & - & ND \\
J, 68, M & L & Temporal & 9 & - & \\
\hline
\end{tabular}

IFA=iris fluorescein angiogram. $\mathrm{ND}=$ not done.

hood. In the other five a lesion was noted on routine examination by an optician, general practitioner, or ophthalmologist. As can be seen from Table 1, each had a single lesion which did not involve more than one quadrant of the iris. Fig. 1 shows the appearance of case C. The two clinical photographs were taken five years apart and confirm the static nature of the lesion despite a well defined tumour circulation which was confirmed on fluorescein angiography. None showed a rise in intraocular pressure. Evidence of progressive enlargement of the tumour was shown in one case. None have shown extrascleral or metastatic spread.

Of the histologically proved cases three out of nine (33\%) presented with secondary glaucoma and mild corneal oedema, three others presented with a progressive increase in size of the lesion, and two others were noted on routine eye examination. One patient presented with a spontaneous hyphaema. Four patients were treated surgically shortly after initial presentation with a variety of clinical features. 


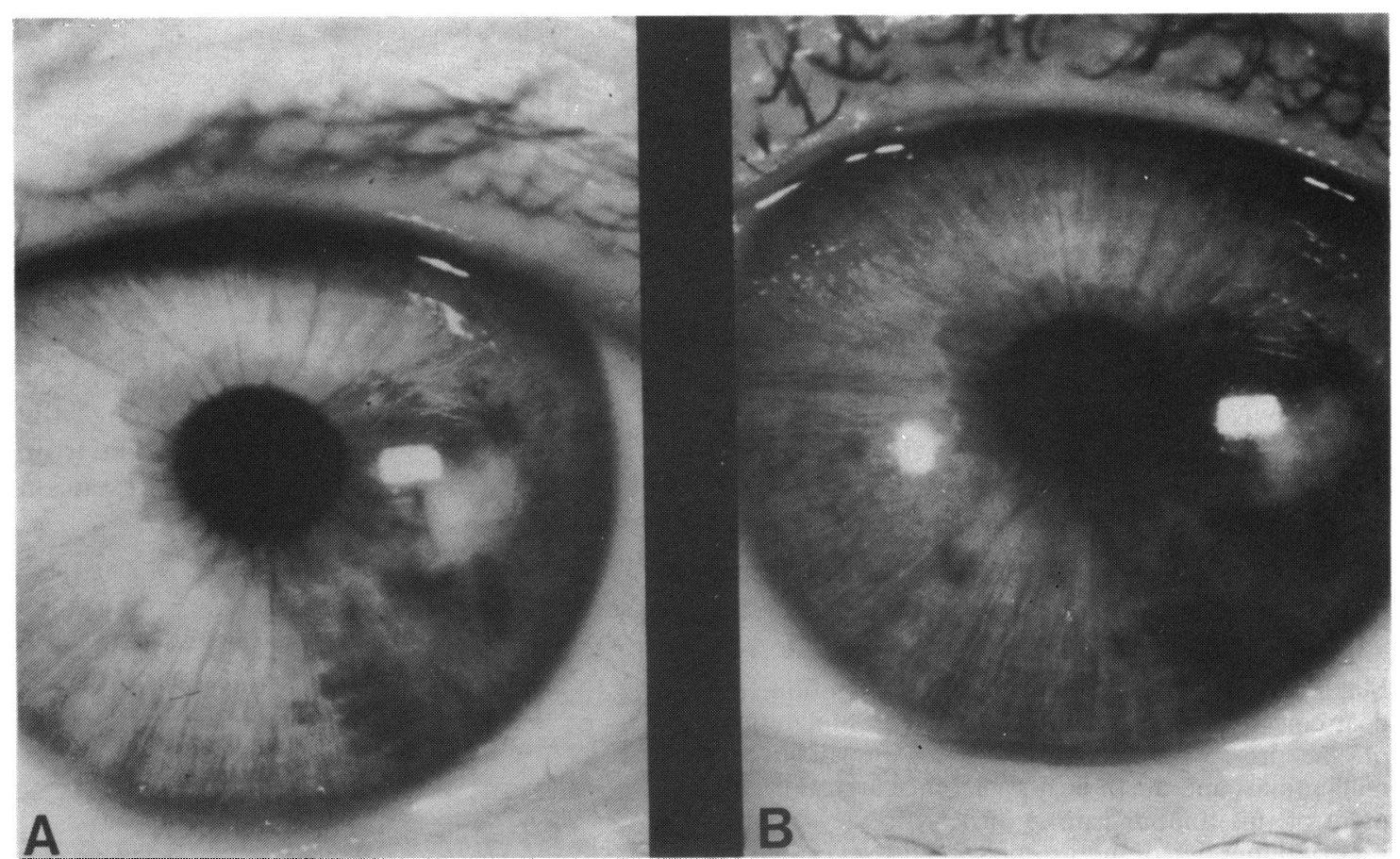

Fig. 1 Quadrantic sized melanoma with amelanotic centre. Photographs taken five years apart showing no change in size. A: March 1978. B: October 1983.

One had evidence of extrascleral spread, two eyes had loss of central vision due to disc cupping, and one patient had presented with a hyphaema. In the remaining five patients the lesions was recorded as growing slowly over the period of observation (range 1-5 years). Fig. 2 shows the clinical growth of the lesion in case 5 over a period of 18 months.

Tables 2 and 3 show the characteristics of the nine cases of histologically proved iris melanoma. Two tumours (22\%) were found to be spindle A cell type, six $(67 \%)$ were spindle $B$ type, and one $(11 \%)$ was a mixed spindle/epithelioid type. Both spindle A melanomas were treated by iridectomy and the patients were alive 10 and 14 years afterwards. Of the six patients with spindle $B$ melanomas three were treated by enucleation and three by iridectomy. The patient with mixed type melanoma was initially treated by iridocyclectomy, but after local recurrence enucleation was performed 14 months later.

Two patients $(22 \%)$ died four and five years after enucleation as a result of metastatic spread of melanoma. Case 1 (mixed type) presented with a distortion of the pupil and a subjective awareness of change in the eye. A local excision was performed. At operation the anterior face of the ciliary body was seen to be invaded. Excision was thought to be incomplete on histological examination. The opera- tion was complicated by lens extraction. Corrected aphakic vision was $6 / 6$. Fourteen months later the residual tumour was increasing in size and enucleation was undertaken. Histology revealed extrascleral extension beneath the conjunctiva in the region of the limbus. Four years after enucleation the patient died from hepatic secondaries.

Case 3 (spindle B cell type) presented with extensive iris invasion and secondary glaucoma. The optic disc was cupped, suggesting a long-standing lesion. There was no clinical evidence of extrascleral spread. Enucleation was undertaken as a primary procedure. The histological report noted gross infiltration of the trabeculum and some extension posteriorly into the anterior face of the ciliary body but no extrascleral spread. Metastatic liver disease was noted at laparotomy five years later and death occurred within nine months.

Of the nine surgical cases four had fluorescein angiography of the anterior segments. All showed obscuration of the normal iris radial vessels and had a distinct tumour circulation within the lesion. Three lesions showed early leakage of the dye, and one lesion showed only late leakage. Of the observed cases eight had anterior segment angiography. Tumour circulation was seen in four of these, with early leakage evident. The remainder showed a 


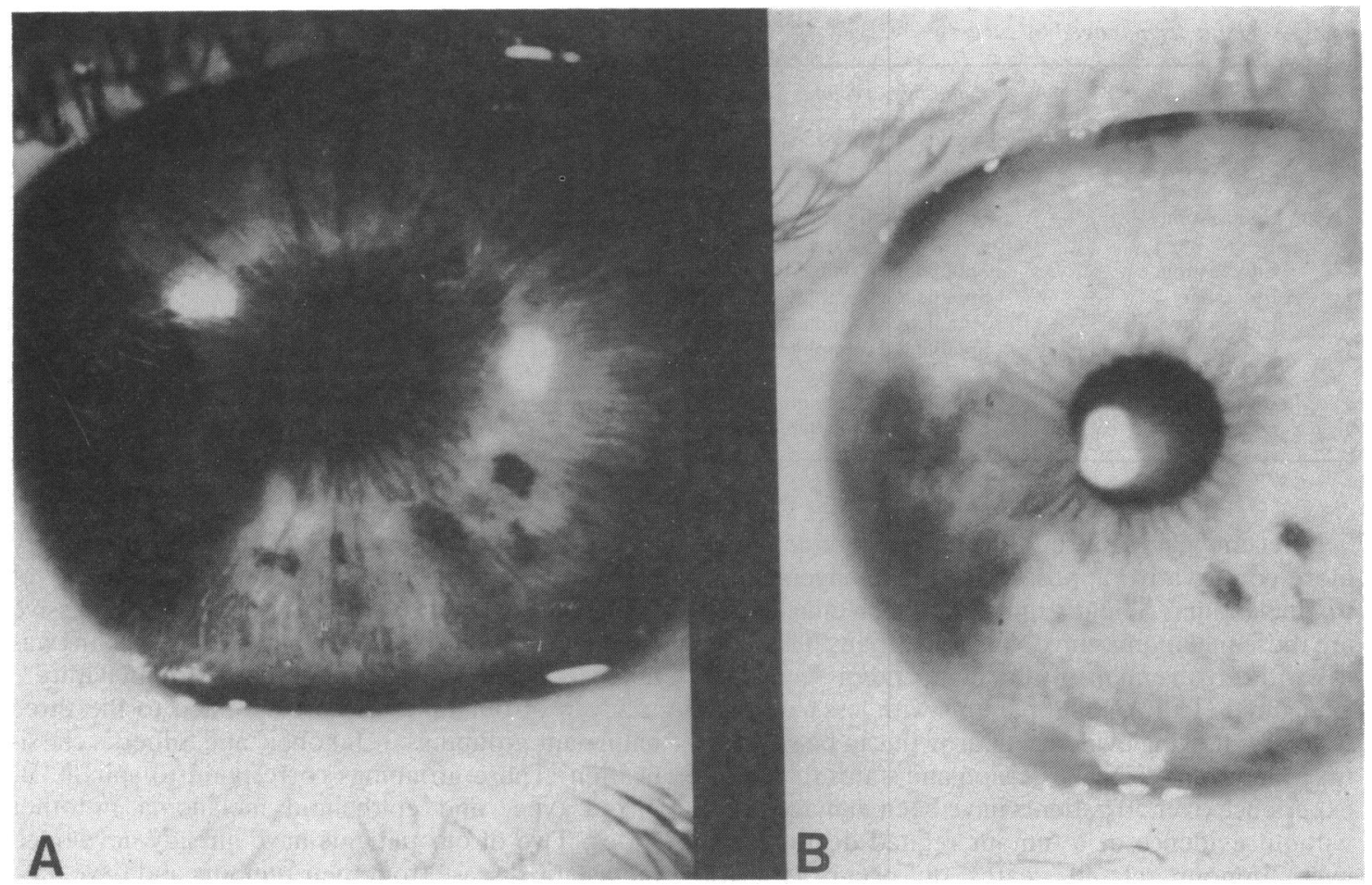

Fig. 2 Nasally located melanoma showing evidence of growth. Photographs taken 18 months apart. A: August 1984. B: February 1986.

variable degree of late leakage from the margins of the lesion (Table 1).

\section{Discussion}

In a study ${ }^{5}$ of choroidal melanoma enucleated in Northern Ireland over a 15-year period (1965-80) 100 cases were reported. In our study over a similar period (1973-87) nine histologically proved iris melanomas were treated surgically. Thus iris melanomas constitute approximately $9 \%$ of uveal melanomas. This correlates well with the findings of

Table 2 Patients managed by surgery

\begin{tabular}{lllll}
\hline $\begin{array}{l}\text { Patient, } \\
\text { age, sex }\end{array}$ & Eye & Location & Presentation & IFA \\
\hline $1,62, \mathrm{~F}$ & $\mathrm{~L}$ & Nasal & $\uparrow$ size & ND \\
$2,49, \mathrm{M}$ & $\mathrm{L}$ & Inferonasal and satellites & $\uparrow$ IOP & Vessels \\
$3,47, \mathrm{~F}$ & $\mathrm{~L}$ & Inferotemporal & $\uparrow$ IOP & ND \\
$4,79, \mathrm{M}$ & $\mathrm{L}$ & Ring & $\uparrow$ IOP & ND \\
$5,43, \mathrm{M}$ & $\mathrm{L}$ & Nasal & $\uparrow$ size & Vessels \\
$6,51, \mathrm{~F}$ & $\mathrm{R}$ & Inferior & Routine & ND \\
$7,55, \mathrm{~F}$ & $\mathrm{~L}$ & Inferonasal & $\uparrow$ size & Vessels \\
$\mathbf{8 , 7 2 , \mathrm { M }}$ & $\mathrm{R}$ & Nasal & Routine & Vessels \\
$9,59, \mathrm{~F}$ & $\mathrm{~L}$ & Inferior & Hyphaema & ND \\
\hline
\end{tabular}

IFA=iris fluorescein angiography. $\mathrm{ND}=$ not done. $\uparrow=$ increasing. other studies. ${ }^{12}$ As is well recognised, iris melanoma has a predilection for the inferior iris. This was confirmed in our series, only one of the tumours being located in the upper half of the iris. The reason for this tendency is unknown, but it is possible that the upper lid protects the superior iris from actinic exposure throughout life, thereby reducing the likelihood of melanocytic proliferation. Shields ${ }^{6}$ states that superiorly placed lesions are sufficiently rare for them to be considered as pseudomelanomas or as an anterior extension from a ciliary body melanoma. In our case $G$ the melanotic lesion was evenly pigmented and slightly elevated, with some ectropion uveae. Only the inner half of the iris stroma was involved, with no extension into the angle or posteriorly. The appearances were therefore in keeping with a primary melanoma.

The average age at diagnosis of all patients with iris melanoma in our study was 61.5 years. This is considerably older (15-20 years) than in other published studies. ${ }^{6}$ Even the histologically proved cases had an average age of 57 years. Two of these gave a history of a melanotic lesion on the iris since adolescence or earlier. There were, however, no cases in our study of patients presenting in adolescence or early adulthood. 
Table 3 Patients managed by surgery

\begin{tabular}{|c|c|c|c|c|}
\hline Patient & Treatment & Pathology & Features & Follow-up \\
\hline 1 & Iridocyclectomy enucleation & Mixed cell & $\begin{array}{l}\text { Invasion of ant. face of ciliary body and } \\
\text { extrascleral spread }\end{array}$ & $\begin{array}{l}\text { Died } 4 \text { years after enucleation, liver } \\
\text { metastases }\end{array}$ \\
\hline 2 & Enucleation & Spindle B & Extrascleral spread & Six months, well \\
\hline 3 & Enucleation & Spindle B & $\begin{array}{l}\text { Invasion of ant. face of ciliary body, no } \\
\text { extrascleral spread }\end{array}$ & $\begin{array}{l}\text { Died } 5 \text { years } 9 \text { months after surgery, liver } \\
\text { metastases }\end{array}$ \\
\hline 4 & Enucleation & Spindle B & Confined to iris, no extrascleral spread & Three years, well \\
\hline 5 & Iridectomy & Spindle B & Complete removal & Two years, well \\
\hline 6 & Iridectomy & Spindle A & Complete removal & Ten years, well \\
\hline 7 & $\begin{array}{l}\text { Iridocyclectomy cataract } \\
\text { extraction }\end{array}$ & Spindle B & Complete removal & Two years, well \\
\hline 8 & Iridectomy & Spindle B & Complete removal & One year, well \\
\hline 9 & Iridectomy & Spindle A & Complete removal & Fourteen years, well \\
\hline
\end{tabular}

In recent years some authors have recommended a more conservative approach in the management of iris melanoma. Shield's indications ${ }^{6}$ for enucleation are those melanomas involving more than $50 \%$ of the iris with involvement of the angle and/or secondary glaucoma. He holds that patients with less extensive tumours showing evidence of growth can be successfully managed by local exicision and states that in his experience over 50 patients have been managed thus without evidence of a tumour related death. However, tumour related deaths do occur with iris melanoma. The study by Sunba $\mathrm{et} \mathrm{al.}{ }^{3}$ reported seven cases of death from a primary malignant melanoma of the iris. Some of these cases had been treated by iridectomy with apparent complete removal of the tumour. An extreme example of the importance of follow-up is reported by Kersten et al., ${ }^{7}$ who recorded a tumour related death 30 years after enucleation. Geisse and Robertson ${ }^{4}$ reviewed the English language literature on iris melanoma and reported a $3 \%$ overall incidence of metastases. Mixed type and epithelioid cell tumours had a metastatic rate of $10.5 \%$ and $6.9 \%$ respectively. Their own series of seven patients, with minimum follow-up of 10 years, had no deaths from metastases. Four of their tumours were spindle $\mathrm{A}$ forms, and it is generally held that metastases do not occur with these melanomas. The clinical problem lies in deciding which lesions are spindle A and which of these will progress to spindle B and epithelioid cytology. Several authors have argued that, since overall mortality rates are so low, all lesions should be observed. Their evidence is based on good long-term survival following local excision. Prolonged survival following excision cannot be equated with low risk in the absence of treatment.

In their series Jakobeic and Silbert ${ }^{8}$ described a nine-part classification of melanocytic lesion. Of their 189 cases $87 \%$ were thought to be benign in cytology and $13 \%$ were assigned to three malignant groups. Invasion of neighbouring structures such as the trabeculum, causing glaucoma, or the ciliary body was not necessarily taken as evidence of malignancy. These were described as 'progressive naevi', and the lack of any tumour-related deaths was taken as evidence of their inherently benign nature.

Seven of our tumours corresponded to the three malignant groupings in Jakobeic and Silbert's classification. These groupings correspond to spindle B, mixed type, and epithelioid melanoma in other series. Two of our patients have already developed metastatic disease from their tumours and have died four years and five years nine months after enucleation. Both of these cases showed invasion of the anterior face of the ciliary body and one presented with secondary glaucoma. A clinical assessment of invasion of the anterior ciliary body is difficult, and if this is an important prognostic indicator then earlier local excision is indicated. Local excision, however, is not without problems. Since most of these lesions occur in the inferior iris, an iridectomy can often result in significant glare, and both our patients

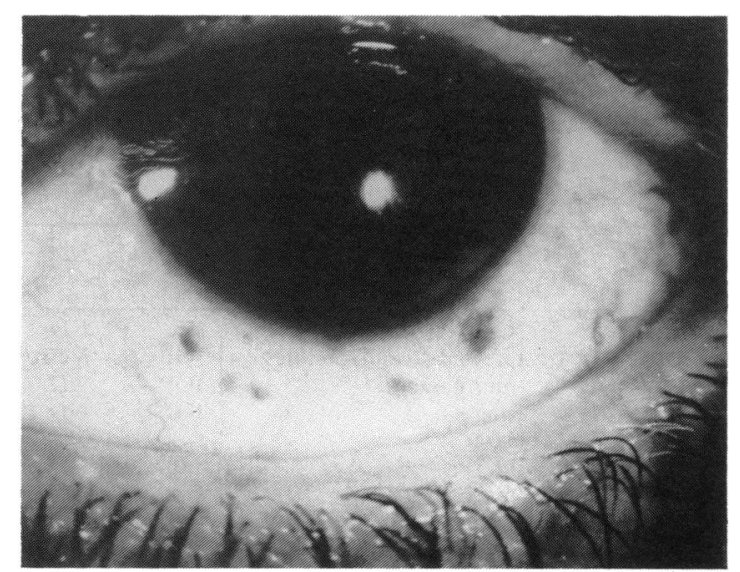

Fig. 3 Large melanoma involving the inferior half of the iris with extrascleral spread evident around the aqueous veins. 
treated by iridocyclectomy required lens extraction.

Extrascleral extension indicating escape from the confines of the scleral envelope and access to the circulation is widely regarded as a bad prognostic sign in choroidal malignant melanoma. ${ }^{9}$ Sunba et al. ${ }^{10}$ identified this as a risk factor for iris melanoma. One of the cases of metastases and one other of our cases. (no. 2) (Fig. 3) were noted to have this on presentation. Follow-up in the latter case has been limited so far, but the prognosis must be guarded. Early identification of those tumours which will progress to invade the ciliary body or pass through the sclera would be of great benefit.

The use of fluorescein angiography has been investigated in the hope that the angiographic features could be correlated with histological type. Demeler ${ }^{11}$ classified the angiographic patterns into three groups and found a correlation between intrinsic vessels with early leakage of dye and a malignant cytology. Conversely the absence of vessels or leakage was shown to be associated with a benign histology. Other authors ${ }^{4}$ have confirmed this general rule but advise that fluorescein angiography should not be used as the final arbiter in the differentiation between benign and malignant lesions. Our results would confirm this, since four of the observed cases in our series showed a definite tumour circulation with early leakage, yet only one showed evidence of clinical growth over an extended period. Fluorescein angiography therefore is a useful ancillary tool in the management of malignant melanoma of the iris.

The criteria applied for observation of iris melanomas in this series have been: $(a)$ no significant growth of the lesion; $(b)$ no evidence of satellite growths; and $(c)$ no evidence of progressive invasion of the trabeculum.

One patient, F, did not comply with these criteria because of refusal of excisional iridocyclectomy. This lesion progressively enlarged, with encroachment on the trabeculum, but the patient was adamant that no surgery be undertaken. Since then he has refused further follow-up but is known to be alive and well at present. All other cases have shown no significant change in the lesion since presentation. Definite conclusions cannot be drawn from those remaining cases, since no histology was available for confirmation and some at least may represent naevi rather than melanomas.

Despite limited follow-up in some patients in our series two of our patients developed metastatic disease, illustrating the potential mortality of enlarging iris melanomas. Early excision before there is invasion of the ciliary body or extrascleral extension would appear to be preferable. Early removal should require less radical surgery than late removal and therefore preserve vision with least complication while removing the malignant focus. This implies the need for close follow-up of the lesions for evidence of growth.

\section{References}

1 Ashton N. Primary tumour of iris. Br J Ophthalmol 1964; 48: 650-68.

2 Rones B, Zimmerman LE. The prognosis of primary tumors of the iris treated by iridectomy. Arch Ophthalmol 1958; 60: 193205.

3 Sunba MSN, Rahi AHS, Morgan G. Tumors of the uvea. I Metastasizing malignant melanoma of iris. Arch Ophthalmol 1980; 98: 82-5.

4 Geisse LS, Robertson DM. Iris melanomas. Am J Ophthalmol 1985; 99: 638-48.

5 Kidd MN, Lyness RW, Patterson CC, Johnston PB, Archer DB. Prognostic factors in malignant melanoma of the choroid: a retrospective survey of cases occurring in Northern Ireland between 1965 and 1980. Trans Ophthalmol Soc UK 1986; 105: 114-21.

6 Shields JA. Diagnosis and management of intraocular tumors. St Louis: Mosby, 1983: 83-121.

7 Kersten RC, Tse DT, Anderson R. Iris melanoma. Nevus or Malignancy? Surv Ophthalmol 1985; 29: 423-33.

8 Jakobeic FA, Silbert G. Are most iris 'melanomas' really nevi? Arch Ophthalmol 1981; 99: 2117-32.

9 Affeldt JC, Minckler DS, Azen SP, Yeh L. Prognosis in uveal melanoma with extra-scleral extension. Arch Ophthalmol 1980; 98: 1975-9.

10 Sunba MSN, Rahi AH, Morgan G, Donovan H. Prognostic parameters in malignant melanoma of the iris. In: Lownatzsch P, ed. Intraocular tumours. Berlin: Springer, 1983: 120-8.

11 Demeler U. Fluorescein angiographical studies in the diagnosis and follow-up of tumours of the iris and ciliary body. $A d v$ Ophthalmol 1981; 42:1-17.

Accepted for publication 15 December 1988. 